\title{
Thermal conductivity and diffusivity of fine-grained sedimentary rocks
}

\author{
Małgorzata Labus ${ }^{1}$ (1) $\cdot$ Krzysztof Labus ${ }^{1}$
}

Received: 23 October 2017 / Accepted: 17 February 2018/Published online: 27 February 2018

(C) The Author(s) 2018. This article is an open access publication

\begin{abstract}
Thermal conductivity is an important thermophysical rock property, needed for heat flow determination, deep thermal regime determination, and reconstruction of thermal history of sedimentary basin. It is generally accepted that the thermal conductivity of rocks decreases with increasing temperature and increases with increasing pressure, and the effects of temperature and pressure counteract each other. Although many measurements of thermal conductivity of the igneous and metamorphic rocks have been taken, little attention has been paid to sedimentary rocks and heat flow in sedimentary basins. Samples selected for the investigation, representing sedimentary rocks of aleuritic structure, were collected from boreholes (from deep formation, approx. $3000 \mathrm{~m}$ ) and outcrops. The mineral composition was determined with the use of TG/DSC analysis, under inert and oxidizing atmosphere. Thermal conductivity measurements were taken with the use of C-Therm analyser, in directions parallel and perpendicular to the bedding in rock. Thermal conductivity of the examined rocks ranges from 0.96 to $6.06 \mathrm{~W} \mathrm{~m}^{-1} \mathrm{~K}^{-1}$ and is strongly dependent on mineral content and bedding direction.
\end{abstract}

Keywords Thermal conductivity $\cdot$ Diffusivity $\cdot$ Sedimentary rock $\cdot$ C-Therm analyser

\section{Introduction}

Thermal conductivity and diffusivity are important thermophysical rock properties, needed for heat flow determination, deep thermal regime assessment, and reconstruction of thermal history of sedimentary basins $[1,2]$. Thermal conductivity $-k$ - is the heat transferred due to unit temperature gradient under steady-state conditions, through a unit area of a layer of a material of unit thickness. The next property-thermal effusivity-is required in the analysis of time-dependent conditions. It reflects the ability of a material to exchange heat with the environment, i.e. to store or dissipate the heat. Thermal conductivity and effusivity values allow for the calculation of the thermal diffusivity - a property - that describes how quickly a material reacts to a change in temperature. It is a measure of the temperature change in unit volume of a material caused by the heat that flows in unit time through a body of unit area and unit thickness, under unit

Małgorzata Labus

malgorzata.labus@polsl.pl

1 Institute for Applied Geology, Silesian University of Technology, 2 Akademicka St., 44-100 Gliwice, Poland temperature difference between its faces. The investigation of these rock parameters is carried out for the purposes of location of geothermal systems [3, 4, 5], geothermal modelling [6], and rock building materials in the aspect of saving heating energy [7].

Thermal properties are related to mineral composition, compaction (and in consequence porosity), and anisotropy of the rock. The other important factors in the rock formation are volumetric ratios between the solid, liquid, and gaseous phases and moisture content. It is generally accepted that the thermal conductivity of rocks decreases with increasing temperature and increases with increasing pressure, and the effects of temperature and pressure counteract each other [2]. Hence, in some studies, these effects are neglectable; however, it should be noted that it is necessary to consider water saturation for in situ correction of thermal conductivity.

Thermal conductivity of rocks falls usually in the range of $0.40-7.00 \mathrm{~W} \mathrm{~m}^{-1} \mathrm{~K}^{-1}$ [8]. Low values are characteristic for dry, not consolidated sedimentary rocks, as gravels and sands. Higher thermal conductivity values are for most sedimentary and metamorphic rocks, while very high are typical for felsic igneous rocks. Rocks with high quartz content (e.g. quartzite, sandstone), as well as water-saturated rocks, are the best heat conductors [9]. Balckwell and 
Steele [10] provide thermal conductivity values for sandstones in the range of $2.50-4.20 \mathrm{~W} \mathrm{~m}^{-1} \mathrm{~K}^{-1}$, for shale: $1.05-1.45 \mathrm{~W} \mathrm{~m}^{-1} \mathrm{~K}^{-1}$, and for claystone and siltstone: $0.80-1.25 \mathrm{~W} \mathrm{~m}^{-1} \mathrm{~K}^{-1}$.

Although many measurements of thermal conductivity of the igneous and metamorphic rocks have been made, little attention has been paid to sedimentary rocks and heat flow in sedimentary basins $[9,11]$. Geothermal studies of sedimentary rocks are related to hydrocarbon exploration, relating thermal conductivity and burial depth or stratigraphic age [12]. Thermal evolution of source rocks and resulting thermal maturity is dependent on sedimentary basin lithology and the initial thermal conductivity of rocks [1]. In case of sedimentary rocks, especially shales, which tend to be highly anisotropic, the essential information is the direction of thermal conductivity measurement. For the estimation of terrestrial heat flow, the relevant thermal conductivity is that perpendicular to bedding [11].

When analysing mineral content of rocks, the quartz content is regarded to be the first-order factor, since quartz is a perfect heat transmission material, of high thermal conductivity: $6.5-11.3 \mathrm{~W} \mathrm{~m}^{-1} \mathrm{~K}^{-1}$ (parallel to the crystal's optical c-axis) [13].

In case of sedimentary rocks, the important factor is porosity. When the pores are filled with air, which is of low thermal conductivity $\left(0.026 \mathrm{~W} \mathrm{~m}^{-1} \mathrm{~K}^{-1}\right)$, the high porosity obviously decreases thermal conductivity of rock. When air is substituted by water (or brine) under water saturation conditions, the thermal conductivity of rock is higher. Apart from porosity, the origin of a particular sediment is also regarded as a factor, which is controlling thermal conductivity of sedimentary rocks [2].

The purpose of our research was aimed at the determination of thermal conductivity in rocks representing Carpathian flysch belt, the Lublin Basin, and the Baltic Basin, which are prospective for conventional and unconventional hydrocarbons extraction, respectively. Measured values might be useful for the relevant reservoir models development, as well as design of the composition of fracturing fluids, especially the energized fluids and foams. For comparative purposes, the shale rocks from other locations (Sudetic Mts and Holy Cross Mts) have also been examined, which may be of importance as construction material.

In this study, we analysed some samples of fine-grained sedimentary rocks, mostly shales; hence, the important question was the comparison between the thermal conductivity values in parallel and perpendicular direction to the bedding in rocks. In case of shales coming from boreholes, the size of sample is rather small; therefore, the TCi thermal conductivity analyser by C-Therm Technologies (Canada) was used, as it enables quick measurement of a small sample.

\section{Samples and methods}

Samples selected for the investigation, representing sedimentary rocks of aleuritic structure, and slaty or fissile texture, were collected from boreholes (deep formation) or outcrops. The samples represent different geological units and stratigraphic position; their density and porosity were examined by means of AccuPyc 1330 helium pycnometer and GeoPyc 1360 density analyser (Table 1).

Mineralogical composition was determined by XRD analysis on Bruker AXS D8 powder diffractometer, equipped with LynxEye linear semiconductor detector and SOL-XE energy-dispersive detector. Measurements were taken with the use of CoK $\alpha$ lamp, voltage $40 \mathrm{kV}$, intensity $40 \mathrm{~mA}$, angle range $2 \Theta: 6^{\circ}-80^{\circ}$, step $0.014^{\circ}$. The semiquantitative interpretation of results, aided by the Bruker Topas software, does not include the organic matter, in contrast to the thermal methods used (Table 2).

The rock samples were examined with scanning electron microscope FEI Quanta-650 FEG, under the following conditions: accelerating voltage $15 \mathrm{kV}$, current $8-10 \mathrm{nA}$, vacuum $50 \mathrm{~Pa}$.

The thermoreactive components of the examined rocks were identified with the use of TG/DSC analysis, under inert and oxidizing atmosphere. The experiments were performed with thermal analyser NETZSCH STA 449 F3 Jupiter $^{\circledR}$. The temperature range of the measurement was $40-1000{ }^{\circ} \mathrm{C}$, with heating rate of $10 \mathrm{~K} \mathrm{~min}^{-1}$. Gas flow rate was $50 \mathrm{~mL} \mathrm{~min}^{-1}$, in case of the oxidizing atmosphere-synthetic air, and inert atmosphere-nitrogen. The rock samples were powdered and put into the alumina $\left(\mathrm{Al}_{2} \mathrm{O}_{3}\right)$ crucible in amount of about $20 \mathrm{mg}$.

Thermal conductivity and thermal effusivity measurements were taken with the use of $\mathrm{TCi}$ analyser (by $\mathrm{C}$-Therm), under room temperature and atmospheric pressure conditions. Thermal conductivity analyser C-Therm employs modified transient plane source (MTPS) technique. The one-sided, interfacial heat reflectance sensor applies a momentary constant heat source to the sample. Measurements consist in recording the voltage change over the source/sensor, while its temperature is slightly increased by an electrical current pulse. The pulse is as short as the sensor element can be considered to be in contact with infinite or semi-infinite solid during the measurement. Measurement time is chosen in a way that the boundaries of the sample do not influence the temperature rise of the element to any measurable extent [14].

Thermal conductivity and effusivity are measured directly, with the precision within 1\% RSD and accuracy within 5\% error. Samples were prepared from the rock so as to have smooth surfaces of diameter at least $17 \mathrm{~mm}$, adapted to the dimensions of the flat surface of the sensor 
Table 1 Geological setting of the samples

\begin{tabular}{llllll}
\hline Sample & Lithology/texture & Stratigraphic position & Geological unit & Localization & Depth/mbgl \\
\hline 1 & Mudstone/fissile & Lower Cretaceous & Carpathian flysch belt & Bystre thrust sheet, Rabe village & Outcrop \\
2 & Mudstone/fissile & & & p. i. & Outcrop \\
3 & Slate/slaty & Lower Carboniferous & Bohemian Massif & Nízký Jesenik, Hořejší Kunčice & Outcrop \\
4 & Shale/fissile & Lower Silurian & Lublin Basin & p. i. & 3640 \\
5 & Shale/fissile & & & p. i. & 3600 \\
6 & Shale/fissile & & Holy Cross Mts. & Bardo Syncline, Prągowiec Ravine & Outcrop \\
7 & Shale/fissile & & Baltic Basin & p. i. & 3160 \\
8 & Shale/fissile & & & p. i. & $1040-1050$ \\
9 & Shale/fissile & & & p. i. & $1730-1740$ \\
10 & Slate/slaty & Cambrian & Bohemian Massif & Kaczawskie Mts., Różana village & Outcrop \\
\hline
\end{tabular}

p. $i$. proprietary information

head. The thickness of the samples was between 20 and $30 \mathrm{~mm}$. Where possible, two such surfaces-parallel and perpendicular to the bedding-have been cut. The contact agent (deionized water) was applied between the sensor and the sample, to reduce the thermal resistance to a negligible level [15]. The final result of the heat conductivity and effusivity was obtained from 10 averaged measurement results in each sample. Thermal diffusivity $\alpha / \mathrm{m}^{2} \mathrm{~s}^{-1}$ was calculated from the thermal conductivity- $k$ / $\mathrm{W} \mathrm{m}{ }^{-1} \mathrm{~K}^{-1}$-and thermal effusivity- $e / \mathrm{W} \mathrm{s} \mathrm{s}^{0.5} \mathrm{~m}^{-2} \mathrm{~K}^{-1}$ :

$\alpha=\frac{k^{2}}{e^{2}}$

based on the following relationships:

$$
\begin{aligned}
\alpha & =\frac{k}{\rho C_{\mathrm{p}}} \\
e & =\sqrt{k \rho C_{\mathrm{p}}},
\end{aligned}
$$

where $\rho$ material density $/ \mathrm{kg} \mathrm{m}^{-3}$ and $C_{\mathrm{p}}$ heat capacity/ $\mathrm{J} \mathrm{kg}^{-1} \mathrm{~K}^{-1}$.

\section{Results}

\section{TG/DSC analysis}

The thermally active minerals detectable in the analysed samples are: clay minerals, muscovite, quartz, calcite, and pyrite (Table 2). Most of the samples contain also some amount of organic matter, which is manifested as exothermal effect (combustion) on DSC curves under oxidizing atmosphere. Under inert atmosphere, the weak endothermic peak on DSC curve, connected to mass loss on TG curve, reflects pyrolysis of the organic matter $[15,16]$.

The presence of relatively abundant clays is shown by dehydration effect in the temperature up to 250 or $300{ }^{\circ} \mathrm{C}$ and dehydroxylation effect in the range of $430-685{ }^{\circ} \mathrm{C}$. In this type of rocks (shales and shists), a fairly common mineral is muscovite, detectable by dehydroxylation reaction in high temperatures $\left(625-1000{ }^{\circ} \mathrm{C}\right)$.

In samples $1,2,4$, and 8, the significant amounts of calcite are present, evident from endothermal reactions between 600 and $860{ }^{\circ} \mathrm{C}$, connected to clearly visible weight loss.

One of the examined samples (10) does not show almost any weight loss effect, what suggested the absence (or only a minor amounts) of thermoreactive components, apart from quartz, which is manifested by strong endothermic effect on DSC curve, with maximum at about $573{ }^{\circ} \mathrm{C}$. The other components of this rock include also feldspars, which are not thermally active minerals.

\section{Thermal conductivity, effusivity, and diffusivity}

The obtained results of the thermal properties are presented in Table 3 and Fig. 1. Thermal conductivity of the examined rocks ranges from 0.96 to $6.06 \mathrm{~W} \mathrm{~m}^{-1} \mathrm{~K}^{-1}$. This parameter measured in the direction parallel to the rock bedding $\left(k_{\mathrm{II}}\right)$ is in range of $2.22-5.85 \mathrm{~W} \mathrm{~m}^{-1} \mathrm{~K}^{-1}$, when perpendicular to the bedding $\left(k_{\perp}\right)$-in the range of $0.96-6.06 \mathrm{~W} \mathrm{~m}^{-1} \mathrm{~K}^{-1}$. The difference between values of $k_{\mathrm{II}}$ and $k_{\perp}$ for each sample usually is significant (Fig. 1) and is expressed by anisotropy coefficient $\left(k_{\mathrm{II}} / k_{\perp}\right)$. In most cases, anisotropy value is well over 1 , which means higher values of $k_{\mathrm{II}}$ than $k_{\perp}$. In case of sample 5 , when anisotropy is lower than $1, k_{\perp}$ is higher than $k_{\mathrm{II}}$.

Effusivity measured along the bedding is between 2064.2 and $3656.8 \mathrm{~W} \mathrm{~s}^{0.5} \mathrm{~m}^{-2} \mathrm{~K}^{-1}$, while in the range 1407.1-3734.9 $\mathrm{W} \mathrm{s}^{0.5} \mathrm{~m}^{-2} \mathrm{~K}^{-1}$ in perpendicular direction. Thermal diffusivity values in the direction parallel to the bedding fall between $11.3 \times 10^{-7}$ and 


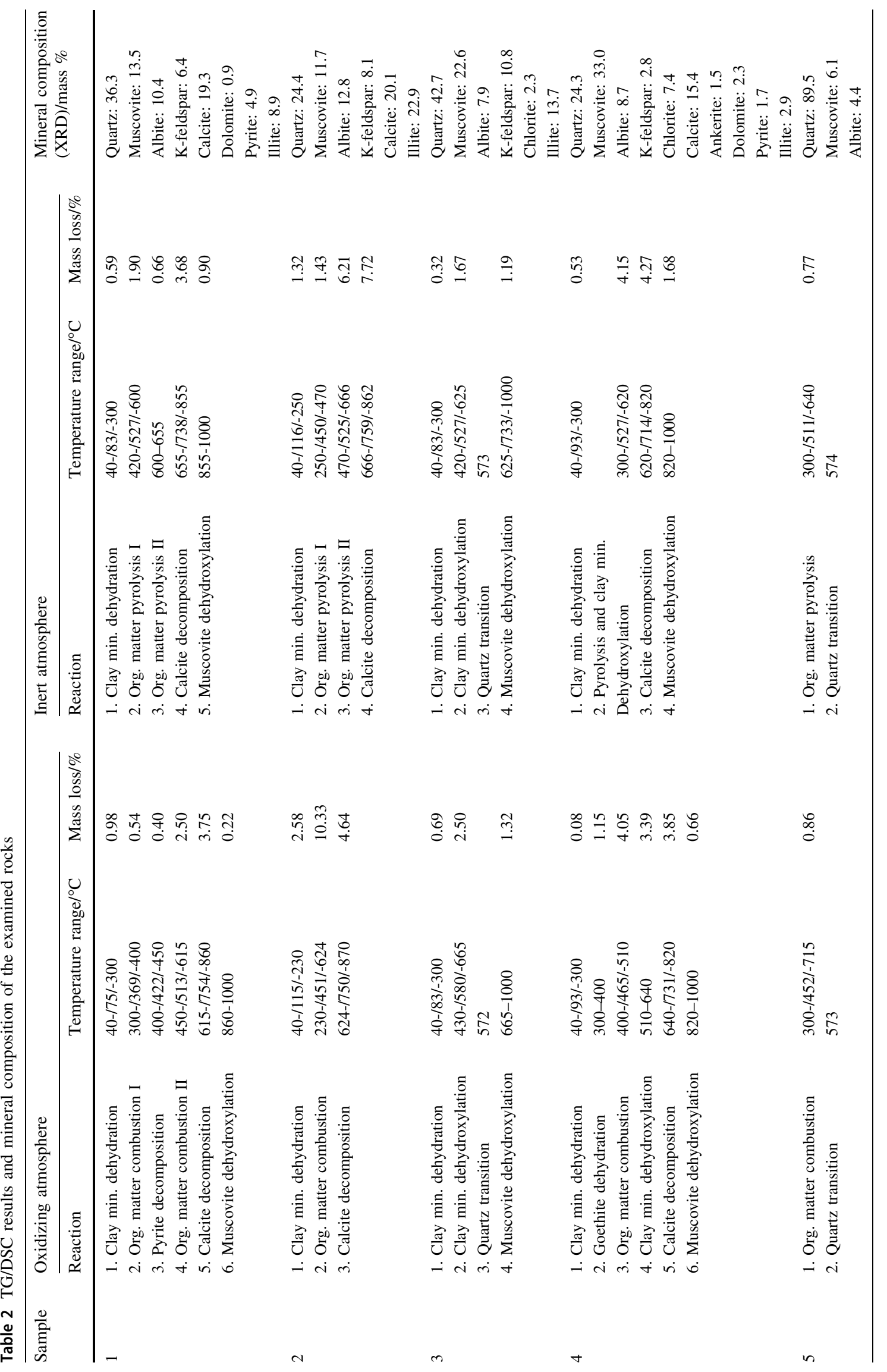




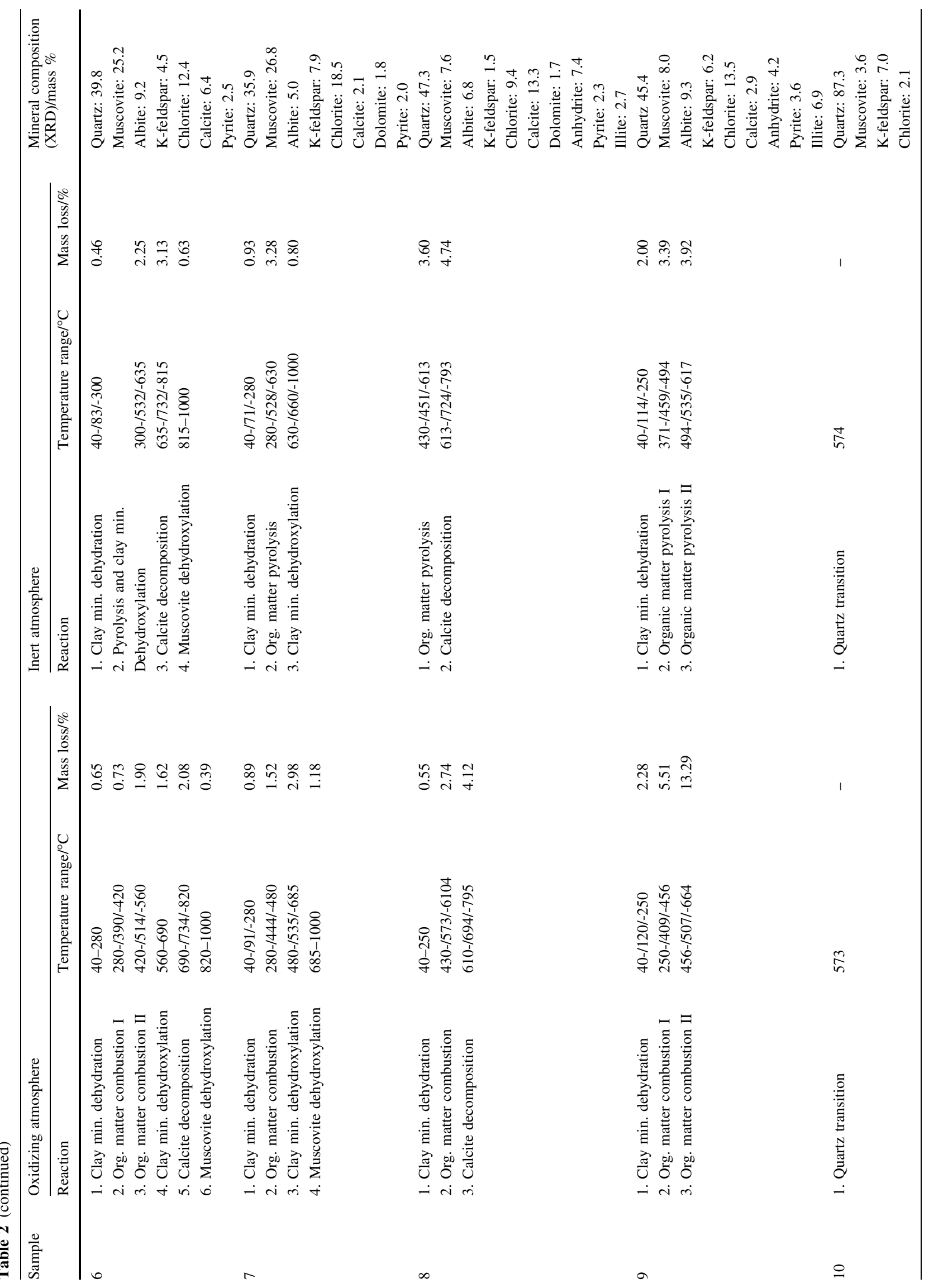


Table 3 Thermal properties, bulk density, and porosity of the samples

\begin{tabular}{|c|c|c|c|c|c|c|c|c|c|}
\hline \multirow[t]{2}{*}{ Sample } & \multicolumn{2}{|c|}{$\begin{array}{l}\text { Average thermal } \\
\text { conductivity } k / \mathrm{W} \mathrm{m}^{-1} \mathrm{~K}^{-1}\end{array}$} & \multirow[t]{2}{*}{$\begin{array}{l}\text { Anisotropy } \\
k_{\mathrm{II}} / k_{\perp}\end{array}$} & \multicolumn{2}{|c|}{$\begin{array}{l}\text { Average effusivity } e \text { l } \\
\mathrm{W} \mathrm{s} \mathrm{s}^{0.5} \mathrm{~m}^{-2} \mathrm{~K}^{-1}\end{array}$} & \multicolumn{2}{|c|}{$\begin{array}{l}\text { Average diffusivity } \alpha / \\
1 \times 10^{-7} \mathrm{~m}^{2} \mathrm{~s}^{-1}\end{array}$} & \multirow[t]{2}{*}{$\begin{array}{l}\text { Bulk density } \\
\rho / \mathrm{g} \mathrm{cm}^{-3}\end{array}$} & \multirow[t]{2}{*}{ Porosity $n / \%$} \\
\hline & $k_{\mathrm{II}}$ & $k_{\perp}$ & & $e_{\mathrm{II}}$ & $e_{\perp}$ & $\alpha_{\text {II }}$ & $\alpha_{\perp}$ & & \\
\hline 1 & 3.34 & 1.58 & 2.1 & 2620.3 & 1750.3 & 16.2 & 8.1 & 2.63 & 5.3 \\
\hline 2 & 2.37 & 0.96 & 2.5 & 2210.9 & 1407.1 & 11.5 & 4.7 & 2.58 & 4.1 \\
\hline 3 & 2.24 & 1.48 & 1.5 & 2064.2 & 1696.3 & 11.8 & 7.6 & 2.60 & 3.3 \\
\hline 4 & 2.22 & 1.34 & 1.7 & 2085.4 & 1622.9 & 11.3 & 6.8 & 2.52 & 8.5 \\
\hline 5 & 4.49 & 6.06 & 0.7 & 3122.3 & 3734.9 & 20.7 & 26.3 & 2.59 & 1.7 \\
\hline 6 & 2.68 & 1.54 & 1.7 & 2310.2 & 1730.9 & 13.4 & 7.9 & 2.64 & 3.6 \\
\hline 7 & 3.95 & 1.32 & 3.0 & 2891.2 & 1428.3 & 18.6 & 8.6 & 2.65 & 3.2 \\
\hline 8 & 4.78 & 1.32 & 3.6 & 3060.0 & 1608.1 & 24.4 & 6.7 & 2.67 & 3.0 \\
\hline 9 & 4.25 & 1.12 & 3.8 & 2913.4 & 1495.6 & 21.3 & 5.6 & 2.65 & 3.8 \\
\hline 10 & 5.85 & 2.06 & 2.8 & 3656.8 & 2003.9 & 25.5 & 10.6 & 2.61 & 0.9 \\
\hline
\end{tabular}

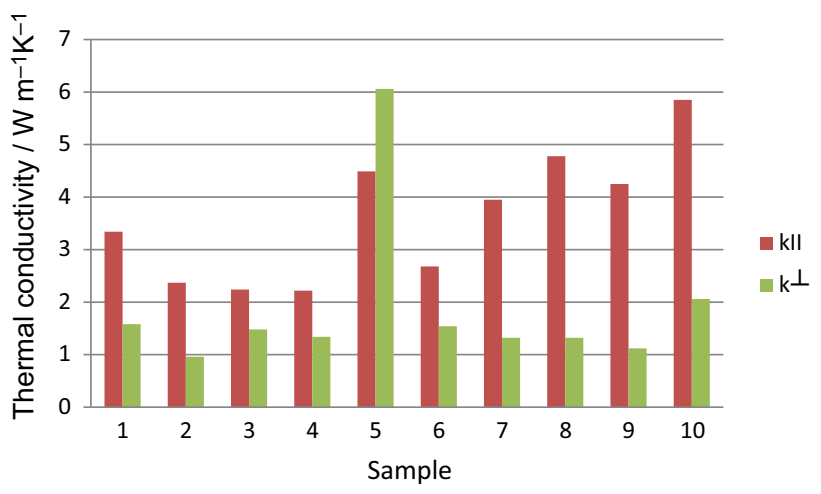

Fig. 1 Thermal conductivity of analysed samples

$25.5 \times 10^{-7} \mathrm{~m}^{2} \mathrm{~s}^{-1}$, while in perpendicular direction range between $4.7 \times 10^{-7}$ and $26.3 \times 10^{-7} \mathrm{~m}^{2} \mathrm{~s}^{-1}$.

\section{Discussion}

Thermal conductivity values of the examined rocks are located in a very wide range from 0.96 to $6.06 \mathrm{~W} \mathrm{~m}^{-1} \mathrm{~K}^{-1}$. When comparing this range to the values provided by Blackwell and Steele [10], we can notice that the lowest values are within the range given for claystone and siltstone $\left(0.80-1.25 \mathrm{~W} \mathrm{~m}^{-1} \mathrm{~K}^{-1}\right)$. Samples 2 (Carpathian flysch-outcrop) and 7 (Baltic Basin-deep well) reveal relatively low values of thermal conductivity in both directions (parallel and perpendicular to bedding). The probable cause is the significant fraction of organic matter in these samples. On the other hand, thermal conductivity for samples 10 (Kaczawskie Mts.-outcrop) and 5 (Lublin Basin-deep well) is very high, typical for rocks of high quartz content, which is confirmed in our case by the TG/DSC and XRD investigation (Table 2). Of course the other components, not thermally active (e.g. feldspars), are also present in sample 10. Porosity is also the factor significantly influencing thermal conductivity; for example, the values of heat conductivity of dry granites range from $2.12 \mathrm{~W} \mathrm{~m}^{-1} \mathrm{~K}^{-1}$ for rocks with high porosity to $3.12 \mathrm{~W} \mathrm{~m}^{-1} \mathrm{~K}^{-1}$ for those with low porosity [17]. In case of the analysed samples, no distinct regularity of this kind was verified. Extremely high thermal conductivity $k_{\perp}$, together with anisotropy value equal to 0.7 , in the quartzbearing sample 5 might be attributed to the existence of microfissures that are perpendicular to the bedding. This should be however verified by microcomputed tomography observations.

The anisotropy of thermal properties in shale rocks is associated with the presence of organic matter laminae, similar to those that were found in the samples tested (Fig. 2) and sheet-silicate minerals, such as clays and micas. Grey and Uher [18] demonstrated that the thermal conductivity parallel to the planes of muscovite and phlogopite was 8-9 times higher than in the perpendicular direction. Also the thermal diffusivity in micas differs by almost a factor of 10 for the two orientations [19].

Sheet silicates tend to be both highly anisotropic and have relatively low conductivity, perpendicular to the bedding plane of the sedimentary rocks in which they are found [11]. Blackwell and Steele [10] found that the thermal conductivity of Palaeozoic shales in Kansas, measured parallel to bedding, is about 2-3 times higher than that perpendicular to bedding. In case of our examinations, the anisotropy coefficient is between 0.7 and 3.8. The highest values are for samples 7, 8, 9, and 10 .

High anisotropy of thermal conductivity of rocks with visible foliation might be interpreted as an alternation of strong and weak conductive layers (quartz and mica layers) [20], together with a high content of oriented minerals with 

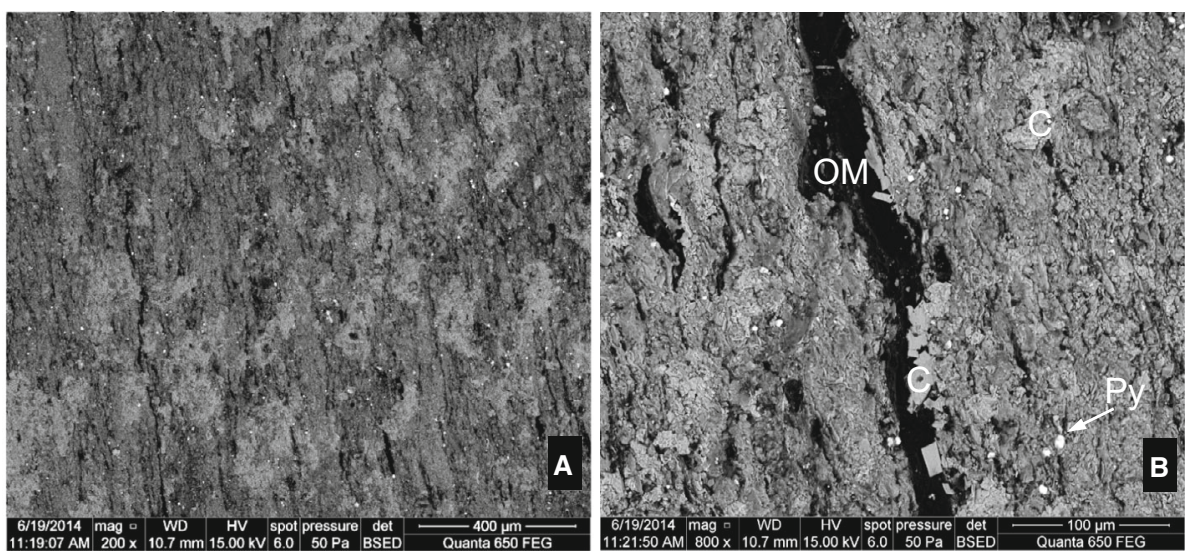

Fig. 2 SEM image of sample 8. a Distinct foliation; light grey fields—calcite aggregates, white dots—pyrite. b A fracture filled with organic matter-OM and calcite crystals- $\mathrm{C}$; Py—pyrite

strong anisotropy (mica) (see Vosteen and Schellschmidt [21]).

As it was reported by many researchers, thermal conductivity of rocks from outcrops is not representative, compared to the core samples from the formation of the same age [1]. On the other hand, investigations performed by Sowiżdżał and Kaczmarczyk [4] revealed no linear relationship between the depth of sampling and rock thermal conductivity. For example, samples 1 and 2, from the outcrops of Carpathian flysch belt, have higher porosities and thermal conductivity (and effusivity) than a singleshale sample no 4, from a deep well, representing unconventional reservoir rock of the Lublin Basin. In case of our examination, we can also compare Silurian shales, from which samples $4,5,7,8$, and 9 come from deep formation (from 1000 to over $3600 \mathrm{mbgl}$ ), when sample 6 is taken from outcrop in Holy Cross Mountains (Poland). The $k$ value for this sample is in the lower middle range values for all Silurian rock samples; hence, in this case the difference between samples from outcrops and drilling holes is not observed. However, if one pays attention to the values obtained for the other samples from outcrops (samples 1-3), a similar level of thermal conductivity for these rocks is noticeable.

The Earth materials representing good or bad conductors are always good or bad diffusers, respectively, as described for the condensed matter examples [22]. This is clearly visible on the graph (Fig. 3) presenting thermal conductivity versus thermal diffusivity of the analysed samples; however, this relationship is not directly proportional. For example, samples 2 (Carpathian flysch-outcrop) and 5 (Lublin Basin-deep well) have slightly lower diffusivity values than could be expected from their conductivity. In general, it could be concluded, however, that the higher is the $\mathrm{k}$ value of the rock (the higher amount of energy from a

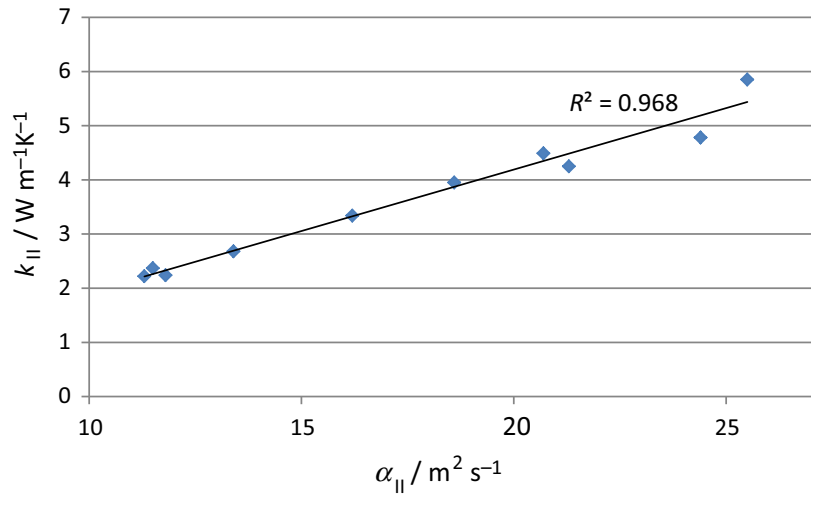

Fig. 3 Thermal conductivity $\left(k_{\mathrm{II}}\right)$ versus thermal diffusivity $\left(\alpha_{\mathrm{II}}\right)$ for analysed samples

thermal source could be extracted), the quicker the absorbed energy is diffused through it.

\section{Conclusions}

In the present work, the thermal conductivity of finegrained sedimentary rocks, sampled from boreholes and outcrops, was analysed in laboratory scale. Thermal conductivity of the examined rocks ranges from 0.96 to $6.06 \mathrm{~W} \mathrm{~m}^{-1} \mathrm{~K}^{-1}$. The measured parameter is strongly dependent on the composition of mineral assemblage and bedding direction.

The presence of organic matter reduces thermal conductivity of rocks. Samples of high quartz content reveal the highest values of thermal conductivity. On the other hand, the elevated values may be attributed to the rock features that rather are mutually exclusive: lower porosity or higher water saturation in the samples. 
Thermal conductivity measured in direction parallel to the rock bedding is usually 1.5-3.8 times higher than measured perpendicular to the rock bedding. The anisotropy of thermal conductivity in shale rocks is connected to the presence of organic matter laminae or sheet-silicate minerals, such as clays and micas.

Considering that all possible discrepancies could have been caused by different factors, it is important to choose the representative samples from wells or outcrops. The rock structure may be disturbed due to the release of stress (e.g. exfoliation) or weathering, respectively, or even by inappropriate sampling. Microcomputed tomography (MCT) analyses might be efficient in examining anisotropy (foliation), and microfracturing of samples, to aid the interpretation of anisotropy of the thermal properties.

Acknowledgements The research leading to these results has received funding from the Polish-Norwegian Research Programme, operated by the National Centre for Research and Development under the Norwegian Financial Mechanism 2009-2014, in the frame of Project Contract No Pol-Nor/196923/49/2013.

Open Access This article is distributed under the terms of the Creative Commons Attribution 4.0 International License (http://crea tivecommons.org/licenses/by/4.0/), which permits unrestricted use, distribution, and reproduction in any medium, provided you give appropriate credit to the original author(s) and the source, provide a link to the Creative Commons license, and indicate if changes were made.

\section{References}

1. Liu S, Feng Ch, Wang LLC. Measurement and analysis of thermal conductivity of rocks in the Tarim Basin, Northwest China. Acta Geol Sin. 2011;85:598-609.

2. Clauser C, Huenges E. Rock physics and phase relations: a handbook of physical constants. Thermal conductivity of rocks and minerals. Am Geophys Union. 2013;3:105-26.

3. Busby J. Thermal conductivity and diffusivity estimations for shallow geothermal systems. Q J Eng Geol Hydrogeol. 2016;49:138-46.

4. Sowiżdżał A, Kaczmarczyk M. Analysis of thermal parameters of Triassic, Permian and Carboniferous sedimentary rocks in central Poland. Geol J. 2016;51:65-76.

5. Luo J, Jia J, Zhao H, Zhu Y, Guo Q, Cheng C, et al. Determination of the thermal conductivity of sandstones from laboratory to field scale. Environ Earth Sci. 2016;75:1158.
6. Di Sipio E, Chiesa S, Destro E, Galgaro A, Giaretta A, Gola G, et al. Rock thermal conductivity as key parameter for geothermal numerical models. Energy Procedia. 2013;40:87-94.

7. Cha J, Seo J, Kim S. Building materials thermal conductivity measurement and correlation with heat flow meter, laser flash analysis and TCi. J Therm Anal Calorim. 2012;109:295-300.

8. Čermák V, Rybach L. Thermal conductivity and specific heat of minerals and rocks. In: Angenheister G, editor. Landolt-Börnstein: numerical data and functional relationships in science and technology-new series, group V (geophysics and space research), volume la (physical properties of rocks). Berlin: Springer; 1982. p. 305-43.

9. Schön JH. Physical properties of rocks: fundamentals and principles of petrophysics (2nd edition). Dev Pet Sci. 2015;65:499.

10. Blackwell D, Steele J. Heat flow and geothermal potential of Kansas. Biul Kans Geol Surv. 1989;226:267-95.

11. Deming D. Estimation of the thermal conductivity anisotropy of rock with application to the determination of terrestrial heat flow. J Geophys Res Solid Earth. 1994;99:22087-91.

12. Wang A, Sun Z, Liu J, Wan J, Hu B, Yang L. Thermal conductivity and radioactive heat-producing element content determinations for rocks from Zhangzhou region, SE China, and their constraints on lithospheric thermal regime. Environ Earth Sci. 2016;75:1213.

13. Clauser C, Huenges E. Thermal conductivity of rocks and minerals. In: Ahrens TJ, editor. Rock physics and phase relations: a handbook of physical constants. Washington: American Geophysical Union; 1995. p. 105-26.

14. Gustafsson SE. Transient plane source techniques for thermal conductivity and thermal diffusivity measurements of solid materials. Rev Sci Instrum. 1991;62:797-804.

15. Harris A, Kazachenko S, Bateman R, Nickerson J, Emanuel M. Measuring the thermal conductivity of heat transfer fluids via the modified transient plane source (MTPS). J Therm Anal Calorim. 2014;116:1309-14.

16. Labus M. Thermal methods implementation in analysis of finegrained rocks containing organic matter. J Therm Anal Calorim. 2017;129:965-73.

17. Eppelbaum L, Kutasov I, Pilchin A. Applied geothermics. Heidelberg: Springer; 2014.

18. Gray AS, Uher CJ. Thermal conductivity of mica at low temperatures. Mater Sci. 1977;12:959-65.

19. Hofmeister AM, Carpenter PK. Heat transport in micas. Can Miner. 2015;53(3):557-70.

20. Whittington AG, Hofmeister AM, Nabelek PI. Temperature-dependent thermal diffusivity of the Earth's crust and implications for magmatism. Nature. 2009;458(7236):319-21.

21. Vosteen HD, Schellschmidt R. Influence of temperature on thermal conductivity, thermal capacity and thermal diffusivity for different types of rock. Phys Chem Earth. 2003;28:499-509.

22. Salazar A. On thermal diffusivity. Eur J Phys. 2003;24:351-8. 